\title{
Paroxysmal nocturnal hemoglobinuria: new concepts in pathophysiology and treatment
}

This article was published in the following Dove Press journal:

Orphan Drugs: Research and Reviews

I September 2015

Number of times this article has been viewed

\section{Ilene Ceil Weitz}

Jane Anne Nohl Division of Hematology, Keck School of Medicine, University of Southern California, Los Angeles, CA, USA
Correspondence: llene Ceil Weitz Norris Comprehensive Cancer Center, I44I Eastlake Ave, Room 3464, Los Angeles, CA 90033, USA Email iweitz@usc.edu
Abstract: Paroxysmal nocturnal hemoglobinuria $(\mathrm{PNH})$ is a rare hematological disorder characterized by hemolysis, cytopenias, bone marrow dysfunction, and thrombosis. Over the last 20 years, we have seen a dramatic unraveling of the pathophysiology of this rare and complex disorder. As a result, new therapies involving complement inhibition have been developed, changing our understanding of the disease and improving outcomes for affected patients.

Keywords: paroxysmal nocturnal hemoglobinuria, pathophysiology, treatment

\section{Introduction}

In 1866, Sir William Gull described a case of a young "anaemic looking" man with episodes of dark urine (ranging from amber to indigo), most often in the morning, improving as the day went on. ${ }^{1}$ Since this first published case of hemoglobinuria, paroxysmal nocturnal hemoglobinuria $(\mathrm{PNH})$ has remained a rare and complex disorder. In 1888, Stribling recognized that the hemolysis was due to a problem within the red blood cell. ${ }^{2}$ This was confirmed by Van de Burgh who noted that the hemolysis was not related to the "cold" or the Donath Landsteiner reaction. ${ }^{3}$ Crosby et al noted the association of bone marrow failure syndromes and recognized cytopenias as a prominent feature of the disorder. ${ }^{4}$ However, it was not until Hamm and Dingle identified that hemolysis was enhanced in the setting of acidic $\mathrm{pH}$, causing an increased red cell sensitivity to the effects of complement, that the underlying mechanism of the disorder emerged. ${ }^{5,6}$ In the early 1990's, Rosse and Weidmer described the effect of increasing complement concentration causing platelet vesiculation. ${ }^{7}$ During the last 20 years, the pathological defect in PNH, a mutation in the phosphatidylinositol (PI) glycan complementation class A gene $(P I G-A)$, has been identified. ${ }^{8}$ This results in loss of the glycosylphosphadidylinositol (GPI) anchors, which link membrane-bound inhibitors of reactive lysis to the cell membrane. As a result, affected cells are exquisitely sensitive to destruction by complement, explaining Hamm's observations. With this understanding, complement inhibition has been introduced as a therapeutic strategy, with successful improvement in patient outcomes. ${ }^{9-12}$

PNH is an extremely rare disease with an incidence of approximately 16 per million. ${ }^{13}$ Although there is a predominance of cases in individuals 20-30 years of age, the disorder is well described in children and older individuals. ${ }^{13-19}$ The mutation in $P I G$ - $A$ occurs on the active $\mathrm{X}$ chromosome, so males and females are equally affected. ${ }^{8,16}$ Both deletions and frame shifts have been described. ${ }^{8}$ Although multiple genes are involved in the synthesis of the GPI anchor, $P I G-A$ mutation is always 
found in $\mathrm{PNH}$. The gene product is part of a complex that transfers $N$-acetylglucosamine (GlcNAc) to PI to form GlcNAc-PI, the first step in biosynthesis of the GPI anchor. As a consequence, the GPl anchor is not made. ${ }^{14}$ Cells may be completely deficient (type III cells) or have partial anchor expression (type II). ${ }^{16-19}$ These anchors link multiple proteins to the cell membrane. ${ }^{17}$ In $\mathrm{PNH}$, as a result of the loss of the GPI anchor, the cell-bound complement regulators, CD55 (decay accelerating factor) and CD59 (which blocks insertion of the terminal complement complex) are not attached to the membrane. ${ }^{16}$ As a result, the cells are more sensitive to complement-mediated destruction.

\section{Role of complement}

Complement is part of our innate immune system, and is used to fight infection and clear apoptotic cells. Activation of complement can occur through antigen-antibody complexes, inflammatory proteins, stimulation of the lectin pathway by fungal infection, and tumor cells. The alternative pathway ensures that a small amount of complement protein $3 \mathrm{~b}$ $(\mathrm{C} 3 \mathrm{~b})$ is deposited on the cell membrane. Membrane-bound $\mathrm{C} 3 \mathrm{~b}$ has several functions, ie, opsinization, amplification, and enzymatic activity. Opsinization is accomplished by deposition of $\mathrm{C} 3 \mathrm{~b}$ on bacteria, viruses, dying cells, and other pathogens, allowing them to be cleared by splenic macrophages. In addition, $\mathrm{C} 3 \mathrm{~b}$ with the $\mathrm{Bb}$ fragment from Factor B can amplify itself by acting as C3 convertase, creating bundles of $\mathrm{C} 3 \mathrm{~b}$. This allows rapid amplification of complement in the setting of a stimulus. Two $\mathrm{C} 3 \mathrm{~b}$ molecules and $\mathrm{a} \mathrm{Bb}$ fragment function as $\mathrm{C} 5$ convertase, which cleaves $\mathrm{C} 5$ to $\mathrm{C} 5 \mathrm{a}$ and $\mathrm{C} 5 \mathrm{~b}$. C5a is a potent inflammatory and prothrombotic protein. $\mathrm{C} 5 \mathrm{~b}$ binds terminal complement proteins. This accomplishes the third role of complement, which is to punch a hole in a membrane. ${ }^{20}$ In addition, thrombin can enzymatically cleave $\mathrm{C} 5$ to its components, $\mathrm{C} 5 \mathrm{a}$ and $\mathrm{C} 5 \mathrm{~b}$, providing one of the links between the complement system and the hemostatic system. ${ }^{21,22}$ Thrombin, when bound to thrombomodulin, activates thrombin activatable fibrinolysis inhibitor, which degrades C5a and C5b, thereby limiting complement activation. Complement $1 \mathrm{q}$ can stimulate tissue factor mRNA and tissue factor expression on monocytes. Complement $1 \mathrm{q}$ also induces expression of interleukin-6, which can then induce tissue factor expression on monocytes. ${ }^{23}$ Pentraxins are inflammatory proteins released from neutrophils, and directly activate the complement system by binding to complement 1q. ${ }^{24}$ Activation of complement, inflammation, and thrombosis appear to be intimately linked in $\mathrm{PNH}{ }^{25}$
Regulation of the complement system occurs by several pathways. Inactivation of $\mathrm{C} 3 \mathrm{~b}$ can occur by the fluid phase regulators Factor I and its cofactor Factor $\mathrm{H}$, membrane cofactor protein, and membrane-bound CD55. As a result, $\mathrm{C} 3 \mathrm{~b}$ cannot bind $\mathrm{a} \mathrm{Bb}$ fragment and cannot function as a convertase. CD59 blocks insertion of C9, the terminal complement protein, into the membrane. ${ }^{20}$ These two proteins, which are linked to the cell membrane by the GPI anchor, are deficient in PNH, leading to increased cell-bound complement. ${ }^{15}$

Although, historically considered a hemolytic disease, we now know that PNH is a true stem cell disorder affecting all the bone marrow-derived cells, including platelets, granulocytes, monocytes, and lymphocytes. Cytopenias may occur as a result of bone marrow failure, aplasia, or hypoplasia, but also as a consequence of the complement-induced cellular injury. ${ }^{4,25}$ Anemia, thrombocytopenia, and neutropenia may occur even in the absence of marrow aplasia or hypoplasia. ${ }^{13,14,25}$ The association of aplastic anemia with the presence of a PNH clone is well recognized. ${ }^{4,26}$ Recent evidence suggests that the T-cell attack in aplastic anemia may be directed to the GPI anchor. ${ }^{27}$ As a result, the normal marrow cells are destroyed but the GPI anchor-deficient cells, ie, PNH cells, may persist. It is also known that $75 \%$ of patients with aplastic anemia will retain their PNH clone with marrow recovery after immunosuppressive therapy; $30 \%$ of those patients will expand the PNH clone and may develop clinical PNH. ${ }^{26}$ The reason why this clonal expansion occurs is not known. Polymorphisms in gamma interferon genes have been reported in $\mathrm{PNH}$, resulting in increased expression of gamma interferon in lymphocytes, blood, and marrow. ${ }^{28,29} \mathrm{PNH}$ cells appear to have relative resistance to the apoptotic effects of gamma interferon on the bone marrow. ${ }^{29} \mathrm{~A}$ recent genomic analysis of patients with aplastic anemia confirms the findings of $P I G-A$ mutations in this disorder, as well as the association of $P I G$ - $A$ with a more favorable outcome in response to immunosuppressive therapy. ${ }^{30,31}$ However, not all cytopenias in PNH are due to marrow failure. Cellular activation and clearance of damaged cells can cause cytopenias, which may improve with complement inhibition. ${ }^{25}$

Hemolysis is the most obvious manifestation of the increased complement activation of PNH cells. Although hemolysis occurs continuously in $\mathrm{PNH}$, the paroxysms represent episodes of increased complement activation. Clinical settings in which complement activation is increased, such as infection, lipopolysaccharide vaccinations, pregnancy, and surgery, are associated with worsening signs and symptoms of PNH. Hemolysis, thrombocytopenia, and 
hemostatic activation, as evidenced by increases in plasma D-dimer with thrombosis, occur during paroxysms. ${ }^{25}$ During these episodes, symptoms such as abdominal pain, dysphagia, weakness, fatigue, and dyspnea become worse. ${ }^{25,32-34}$

\section{Morbidity and mortality in PNH}

Long considered a benign hematological disorder, $\mathrm{PNH}$ is associated with significant morbidity and mortality. Historical data suggest that $35 \%$ of patients will die within 5 years of diagnosis, and that $50 \%$ will die within 10 years in spite of best supportive care. ${ }^{13}$ Thrombosis is the most common cause of death, but renal failure and pulmonary hypertension contribute to the overall mortality. ${ }^{13,33,34}$ Symptoms such as chest pain, dyspnea, and abdominal pain are highly predictive of thromboembolic complications. ${ }^{34}$ Fatigue is the most prominent symptom, and is experienced by $97 \%$ of patients. ${ }^{35}$ The fatigue and dyspnea are independent of the degree of anemia, and probably reflect cytokine (interleukin-6) activation and pulmonary hypertension. ${ }^{25,35,36}$ In an analysis by Hill et al, pulmonary hypertension, as measured by N-terminal pro-brain natriuretic peptide, was present in $47 \%$ of $\mathrm{PNH}$ patients. This may reflect pulmonary artery spasm due to nitric oxide consumption as well as chronic pulmonary emboli. ${ }^{36,37}$ Reduction in hemolysis, as measured by lactate dehydrogenase $(\mathrm{LDH})$, results in a decrease in consumption of nitric oxide with improvement in the pulmonary hypertension. ${ }^{36,37}$

Abdominal pain frequently accompanies a "paroxysm". Historically, this pain has been attributed to smooth muscle dystonia associated with nitric oxide consumption due to hemolysis. However, analysis of the South Korean PNH Registry data demonstrates an increased risk of thromboembolic events with abdominal pain, particularly when the LDH is elevated. ${ }^{34}$ This most likely represents ischemia due to small vessel occlusion. Using tagged platelets, one can demonstrate labeled platelets adhering to the abdominal vasculature in thrombocytopenic $\mathrm{PNH}$ patients, which is not seen in patients with other forms of thrombocytopenia (such as idiopathic thrombocytopenic purpura). ${ }^{38}$

\section{Renal failure}

Renal insufficiency is an under recognized complication of PNH. Acute renal failure has long been a recognized consequence of a paroxysm in $\mathrm{PNH}$, and chronic renal failure has been reported in $8 \%-18 \%$ of $\mathrm{PNH}$ patients. Chronic intravascular hemolysis leads to deposition of iron in the tubular cells, causing interstitial nephritis. In addition, thrombosis within the kidney can lead to glomerular loss. ${ }^{39}$ Hillmen et al reported a $60 \%$ incidence of renal insufficiency in patients participating in the clinical trials of eculizumab. Of those patients, $20 \%$ had stage 3-5 kidney disease as defined by the National Kidney Foundation criteria. ${ }^{40}$

\section{Thrombosis}

By far the most destructive complication of $\mathrm{PNH}$ is thrombosis, which accounts for most of the deaths (60\%) and end organ damage. At least $18 \%$ of Asian patients and $40 \%$ of Caucasian patients with PNH have thromboembolic complications. ${ }^{13,14,33,34,41}$ However, no significant correlations with inherited thrombophilias have been noted. ${ }^{42}$ Analysis of the French registry subsequently revealed that $30 \%$ of aplastic PNH patients developed thromboembolic complications. ${ }^{33}$ Venous events predominate (85\%), although arterial events, such as myocardial infarction and stroke (15\%), have been reported. ${ }^{13,34}$ Unusual thromboembolic events, such as Budd-Chiari syndrome, mesenteric thrombosis, cavernous sinus thrombosis, and skin necrosis are seen more frequently in patients with $\mathrm{PNH}$ than in the general population. ${ }^{13,34}$ There is a 60-fold increase in ischemic stroke in PNH which occurs at a much younger age (median 43 years) when compared with the unaffected population ( 73 years). ${ }^{43}$

The pathophysiology of thrombosis in PNH is complex. Historically, thrombosis was attributed to hemolysis, but recent data in the setting of complement inhibition suggest that this is not likely. While nitric oxide consumption from intravascular hemolysis is associated with arterial and pulmonary artery constriction, it does not induce generation of thrombin, and red cell vesicles do not express tissue factor. In addition, venous rather than arterial events predominate ( $85 \%$ venous versus $15 \%$ arterial). ${ }^{13,34}$ Neither the presence of hemolysis nor the degree of anemia influence the rate of thrombosis. ${ }^{17,44}$ Red cell vesicles make up a small fraction of the circulating microparticles in PNH. ${ }^{45}$ Most are derived from monocytes, platelets, and endothelial cells. ${ }^{45-47}$ Hemoglobinuria, the clinical indicator of intravascular hemolysis, does not correlate with an increased risk of thromboembolic complications unless combined with an increased LDH level. ${ }^{34}$ In other complement disorders, such as atypical hemolytic uremic syndrome, hemolysis is secondary to the microvascular thrombosis. ${ }^{48-50}$ However, free heme in the plasma does activate more complement by the alternative pathway, worsening the disorder. ${ }^{51}$ Most importantly, markers of hemostatic activation do not correlate with the LDH level, suggesting that thrombosis occurs by a pathway independent of hemolysis. ${ }^{25}$

PNH affects all of the bone marrow-derived cells. Platelet activation in PNH is well described. Weidmer and Rosse 
demonstrated platelet vesiculation in response to increasing complement concentrations. In vitro, these vesicles are highly thrombogenic. ${ }^{7}$ Both granulocytes and monocytes are deficient in GPI anchors. Monocyte-derived tissue factorbearing microparticles (TFMP) are increased in PNH and reduced after curative bone marrow transplantation and with complement inhibition. ${ }^{20,45}$ Endothelial damage, with endothelial cell vesiculation and activation, as evidenced by increased expression of von Willebrand factor (vWF), has been demonstrated in $\mathrm{PNH}^{46,52}$ Complement inhibition reduces the expression of vWF in patients with $\mathrm{PNH} .{ }^{52}$ Other potential mechanisms include reduction of endothelial tissue factor pathway inhibitor, which is GPI-linked and therefore deficient in PNH. ${ }^{53}$ Loss of tissue factor pathway inhibitor has been associated with an increased risk of venous and possibly arterial thrombosis. ${ }^{53,54}$ Loss of the GPI-linked urokinase-type plasminogen activator from endothelial cells and monocytes could result in a reduction in the fibrinolytic response to thrombosis. In PNH, intrinsic fibrinolytic activity has been shown to be inversely associated with clone size. ${ }^{55}$

Complement activation generates large amounts of $\mathrm{C} 3 \mathrm{a}$ and $\mathrm{C} 5 \mathrm{a}$. Genetic loss of $\mathrm{C} 3$ abolishes fetal loss in the mouse antiphospholipid syndrome. ${ }^{56}$ In the mouse model of recurrent fetal loss due to antiphospholipid syndrome, recruitment of inflammatory cells by $\mathrm{C} 5 \mathrm{a}$ is crucial in the development of placental insufficiency. ${ }^{56}$ In the sepsis model, recent data suggest a different role for $\mathrm{C} 3 \mathrm{a}$ and $\mathrm{C} 5 \mathrm{a}$. $\mathrm{C} 3 \mathrm{a}$ does not appear to function as a chemoattractant for neutrophils but appears to induce activation of macrophages. In contrast, C5a accounts for the deleterious effects of sepsis, including lung injury and disseminated intravascular coagulation. ${ }^{57}$ $\mathrm{C} 5 \mathrm{a}$ is a potent inflammatory and prothrombotic protein that links the complement and hemostatic systems. Induction of cytokines, such as interleukin-6, by C5a increases expression of tissue factor by monocytes, ultimately leading to thrombosis in the placenta. ${ }^{56}$ Concentrations of C5a as low as $1 \mathrm{nM}$ can rapidly increase the expression of tissue factor in monocytes (Weitz, unpublished data, 2015). C5a interacts with the $\mathrm{C} 5 \mathrm{a}$ receptor to produce thrombotic microangiopathic-like lesions in the mouse that can be prevented by inhibition of complement. ${ }^{56}$ Blockade of the $\mathrm{C} 5 \mathrm{a}$ receptor by a small molecule inhibitor appears to prevent thrombosis in the live in vivo mouse model of thrombosis (Furie, personal communication, 2015). Levels of circulating TFMP are increased in PNH and respond to inhibition of complement. ${ }^{25}$ Small amounts of thrombin generated on the surface of the microparticle can activate and aggregate platelets. ${ }^{58,59}$ In cancer patients, increased circulating
TFMP is associated with an increased risk of thrombosis. ${ }^{60}$ However, unlike in cancer patients, where increased circulating TFMPs are derived from the cancer cell itself, in those with $\mathrm{PNH}$, complement activation is required for microparticle tissue factor expression..$^{25,58-60}$ Of importance, while TFMPs decrease with complement inhibition, total microparticle generation remains flat and does not correlate with markers of hemostatic activation. It is possible that the composition of the microparticles changes with complement inhibition, but it is clear that regardless of the origin, they do not participate in hemostatic activation. ${ }^{24}$

The interaction between $\mathrm{C} 5 \mathrm{a}$ and the $\mathrm{C} 5 \mathrm{a}$ receptor has also been demonstrated to induce plasminogen activator inhibitor-1, altering the balance between thrombosis and fibrinolysis. ${ }^{61}$ Urokinase-type plasminogen activator is GPI-linked and therefore deficient in $\mathrm{PNH} .{ }^{55}$

The role of granulocytes in thrombosis is actively being explored in PNH. C5a and its receptor (C5aR/CD88) mediate the expression of tissue factor in granulocytes. ${ }^{62}$ In addition, complement activation of PNH granulocytes may result in release of enzymes, inflammatory proteins, and histone nets. ${ }^{24,63}$ Granulocyte enzymes can damage the endothelium, causing exposure of the subendothelium. In addition to capturing bacteria, red cells and platelets are trapped by the histone nets, bringing them to the endothelium. ${ }^{61}$ Activated platelets and endothelium expressing P-selectin then bind to the monocyte P-selectin glycoprotein 1, inducing monocyte tissue factor expression. Reduction in soluble P-selectin with complement inhibition correlates with reduction in $\mathrm{LDH}$, reflecting reduction in activation of platelets and endothelial cells. ${ }^{25}$

\section{Complement inhibition}

The development of complement inhibition had dramatically changed both the understanding of PNH as well as the outcomes for patient with the disorder. At present, eculizumab is the only approved complement inhibitor. A highly humanized monoclonal antibody to $\mathrm{C} 5$, eculizumab binds to $\mathrm{C} 5$ with very high affinity. It is thought that eculizumab inhibits the binding of $\mathrm{C} 5$ to the $\mathrm{C} 3 \mathrm{~b}-\mathrm{Bb}-\mathrm{C} 3 \mathrm{~b}$ complex (C5 convertase), blocking the conversion of C5 to C5a, C5b. ${ }^{64,65}$ Proximal $\mathrm{C} 3 \mathrm{~b}$ function is preserved. The antibody does not bind to the Fc receptor and does not fix complement. ${ }^{64,65}$ The antibody is immunoglobulin G4, which does not cross the placenta to any appreciable degree, nor pass into breast milk with any significance. ${ }^{66}$ Four clinical trials in PNH have demonstrated the consistent and reproducible efficacy of eculizumab in inhibiting hemolysis, reducing transfusion requirements, reducing thrombosis, improving renal function, and reducing 
fatigue, independent of recovery of the anemia. ${ }^{9-11,67,68}$ More important, recent data suggest an improvement in survival, matching that in age-matched controls. ${ }^{69}$ This is likely due to the marked reduction (92\%) in thromboembolic complications with eculizumab treatment. ${ }^{10}$

The response rate to eculizumab is extremely high in PNH. However, because the protein has a half-life of 10-12 days, some patients require a shortened interval between doses (12 days) or a higher dose of drug every 14 days. ${ }^{65}$ No significant inhibitory antibodies have been described. Twelve PNH patients (eleven Japanese and one Argentinian [of Asian descent]) were reported to have a single missense polymorphism in C5 (C.2654G $>$ A mutation in the Japanese patients, and a C.2653C $>\mathrm{T}$ mutation in the Argentinian patient), which completely inhibits the effect of eculizumab. ${ }^{70}$ These patients do respond to a $\mathrm{C} 5$ inhibitor binding at a different site on $\mathrm{C} 5$. The mutations are thought to make $\mathrm{C} 5$ inaccessible to eculizumab. ${ }^{71}$ In spite of a reduction in $\mathrm{LDH}, 25 \%-35 \%$ of patients continue to require transfusion support. ${ }^{72}$

Underlying renal dysfunction may contribute to the persistent anemia in a few patients. It has been postulated that accumulation of $\mathrm{C} 3 \mathrm{~b}$ on the surface of the red cell due to $\mathrm{C} 5$ blockade may cause increased extravascular red blood cell clearance by the spleen and liver. ${ }^{73}$ However, a recent report suggests that although patients may have increased $\mathrm{C} 3 \mathrm{~b}$ on their red blood cells, the need for transfusion may be due to insufficient complement blockade. ${ }^{72}$

Eculizumab has been listed as a category $\mathrm{C}$ drug in pregnancy. Pregnancy in patients with $\mathrm{PNH}$ is associated with significant morbidity and mortality, including fetal demise and maternal thromboembolic complications and death. While anticoagulants have been used with some success in some patients with $\mathrm{PNH}$, the morbidity and mortality during pregnancy remain high. ${ }^{73-75}$ There are no randomized trials of eculizumab in pregnant PNH patients. However, several publications have demonstrated improved maternal outcomes, without harm to the fetus, even for women receiving eculizumab from the beginning of pregnancy. ${ }^{66,74,75}$ Transfusion requirements may increase in pregnancy, even while on treatment with eculizumab. In addition, because of the expanded plasma volume, pregnant patients may require a higher dose of eculizumab in the third trimester. ${ }^{66,74,75}$ Most pregnant patients have received anticoagulation with heparin, low molecular heparin, or fondiparinux, in either prophylactic or therapeutic doses, during pregnancy. ${ }^{66,73-75}$ In spite of the excellent pregnancy outcomes with eculizumab, there are no data to suggest that anticoagulation can or should be withheld. ${ }^{75}$ Breakthrough during the peripartum and postpartum period can be associated with an increased risk of thromboembolic events in spite of eculizumab and anticoagulant treament. ${ }^{74,75}$

The biggest risk with eculizumab and inhibition of $\mathrm{C} 5$ is that of Neisseria infection. ${ }^{65}$ All patients must receive polyvalent meningococcal vaccination. These vaccines only cover serotypes A, C, W, and Y. Recently, a serotype B vaccine was approved both in Europe and the USA (for ages 13-25 years). It has been recommended that immunization be given 2 weeks prior to starting eculizumab. However, several cases of stroke have been reported following vaccination (Hill, personal communication, 2013). If the patient needs to start treatment before the 2 weeks, prophylactic ciprofloxacin or penicillin can be given for 14 days. Although continuous antibiotic prophylaxis has not been mandated by the US Food and Drug Administration, several major PNH centers have adopted this strategy with success (Hill and Socie, unpublished data, 2013).

\section{Future directions}

A variety of complement inhibitors are near to or entering clinical trials. Both $\mathrm{C} 5$ and $\mathrm{C} 3 \mathrm{~b}$ inhibitors, as well as alternative pathway inhibitors, $\mathrm{C} 5 \mathrm{a}$ receptor blockers, and small interfering RNA are being studied. PNH remains a fascinating disorder. With complement inhibition, the morbidity and mortality has been dramatically improved. Complement inhibition has also given us remarkable insights into the role of complement in $\mathrm{PNH}$, thrombosis, and other complement-mediated disorders.

\section{Disclosure}

The author has been on the speakers' bureau and advisory board for Alexion Pharmaceuticals. There are no other conflicts of interest in this work.

\section{References}

1. Gull WW. A case of intermittent haematinuria, with remarks. Guys Hosp Rep. 1866;12:381-392.

2. Strubling P. Paroxysmale haemoglobinurie [Paroxysmal hemoglobinuria]. Dtsch Med Wochenschr. 1882;8:17. German.

3. Hijmans van den Berg AA. Ictere hemolytique avec crises hemoglobinuriques. Fragilite globulare [Jaundice hemolysis with crisis. Fragile cells]. Rev Med. 1911;31:63. French.

4. Crosby WH. Paroxysmal nocturnal hemoglobinuria: a report of a case complicated by an aregenerative (aplastic) crisis. Ann Intern Med. 1953;39:1107-1117.

5. Ham TH, Dingle JH. Studies on destruction of red blood cells. II. Chronic hemolytic anemia with paroxysmal nocturnal hemoglobinuria: certain immunologic aspects of the hemolytic mechanism with special reference to serum complement. J Clin Invest. 1939;18:657-672.

6. Ham TH, Hinz CF Jr, Weisman R Jr. Mechanism of destruction of red blood cells in certain hemolytic conditions. Arch Intern Med. 1956;96:574-592. 
7. Weidmer T, Hall SE, Ortel TL, Kane WH, Rosse WF, Sims PJ. Complement-induced vesiculation and exposure of prothrombinase sites in platelets of paroxysmal nocturnal hemoglobinuria. Blood. 1993;82:1192-1196.

8. Takeda J, Miyata T, Kawagoe K, et al. Deficiency of the GPI anchor caused by a somatic mutation of the PIG-A gene in paroxysmal nocturnal hemoglobinuria. Cell. 1993;73:703-711.

9. Hillmen P, Hall C, Marsh JCW, et al. Effect of eculizumab on hemolysis and transfusion requirements in patients with paroxysmal nocturnal hemoglobinuria. N Engl J Med. 2004;350:552-559.

10. Hillmen P, Muus P, Duhrsen U, et al. Effect of the complement inhibitor eculizumab on thromboembolism in patients with paroxysmal nocturnal hemoglobinuria. Blood. 2007;110:4123-4128.

11. Brodsky RA, Young NS, Antonioli E, et al. Multicenter phase 3 study of the complement inhibitor eculizumab for treatment of patients with paroxysmal nocturnal hemoglobinuria. Blood. 2008;111:1840-1847.

12. Kelly RJ, Hill A, Arnold LM, et al. Long term treatment with eculizumab in paroxysmal nocturnal hemoglobinuria; sustained efficacy and improved survival. Blood. 2011;117:6786-6792.

13. Hillmen P, Lewis SM, Bessler M, Luzatto L. Natural history of paroxysmal nocturnal hemoglobinuria. N Engl J Med. 1995;33:1253-1258.

14. Nishimura J, Kanakura Y, Ware RE, et al. Clinical course and flow cytometric analysis of paroxysmal nocturnal hemoglobinuria in the United States and Japan. Medicine (Baltimore). 2004;83:193-207.

15. Pu JJ, Brodsky RA. Paroxysmal nocturnal hemoglobinuria from bench to bedside. Clin Transl Sci. 2011;4:210-224.

16. Bessler M, Mason PJ, Hillmen P, et al. Paroxysmal nocturnal hemoglobinuria $(\mathrm{PNH})$ is caused by somatic mutations in the PIG-A gene. EMBO J. 1994;13:110-117.

17. Fujioka S, Yamada T. Varying populations of CD59-negative, partly positive and normally positive blood cell in different cell lineages in peripheral blood of paroxysmal nocturnal hemoglobinuria patients. Am J Hematol. 1994;45:122-127.

18. Rollinson S, Richards S, Norfolk D, Bibi K, Morgan G, Hillmen P. Both paroxysmal nocturnal hemoglobinuria type III and paroxysmal type involving II cells can arise from different point mutations the same codon of the PIG-A gene. Blood. 1997;89:3069-3071.

19. Bessler M, Mason PJ, Hillmen P, Luzzatto L. A gene causing partial deficiency of the GPI linked surface proteins (PNH II) in patients with paroxysmal nocturnal hemoglobinuria. Br J Haematol. 1994;87: 863-866.

20. Holers VM. Complement and its receptors: new insights into human disease. Anпu Rev Immunol. 2014;32:433-459.

21. Amara U, Flierl M, Rittirsch D, et al. Molecular intercommunication between complement and the coagulation systems. J Immunol. 2010;185:5628-5636.

22. Huber-Lung M, Sarna JV, Zetoune FS, et al. Generation of C5a in the absence of C3: a new complement pathway. Nat Med. 2006;12: 682-687.

23. Landsem A, Nielsen EW, Fure H, et al. C1q inhibitor efficiently inhibits E. coli induced tissue factor mRNA upregulation and monocyte tissue factor expression and coagulation in human whole blood. Clin Exp Immunol. 2013;173:217-229.

24. Jaillon S, Bonavita E, Gentile S, et al. The long pentraxin as a key component of humoral innate immunity and a candidate diagnostic for inflammatory disease. Int Arch Allergy Immunol. 2014;165:165-178.

25. Weitz IC, Razavi, P, Rochanda L, et al. Eculizumab results in rapid and sustained decrease in markers of thrombin generation and inflammation in patients with $\mathrm{PNH}$ independent of its effects on hemolysis and microparticles. Thromb Res. 2012;130:130-138.

26. Sugimori C, Mochizuki K, Qi Z, et al. Origin and fate of blood cells deficient in glycosylphosphatidylinositol anchored proteins among patients with paroxysmal nocturnal haemoglobinuria. Br J Haematol. 2009;147:102-112.

27. Gargiulo L, Papaioannou M, Sica M, et al. Glycosylphosphatidyl inositol-specific, CD1d-restricted T cells in paroxysmal nocturnal hemoglobinuria. Blood. 2013;121:2753-2761.
28. Wang SY, Yang XJ, Wang W, Tian YY, Cao FL, Zhou J. Association analysis of cytokine polymorphisms and plasma level in Northern Chinese Han patients with paroxysmal nocturnal hemoglobinuria. Chin Med J (Engl). 2012;125:1576-1580.

29. Zeng W, Miyazato A, Chen G, Kajigaya S, Young NS, Maciejewski JP. Interferon-gamma-induced gene expression in CD34 cells: identification of pathologic cytokine-specific signature profiles. Blood. 2006;107: 167-176.

30. Yoshizato T, Dumitriu B, Hosokawa K, et al. Somatic mutations and clonal hematopoiesis in aplastic anemia. $N$ Engl J Med. 2015;373: $35-47$.

31. Sugimori C, Chuhjo T, Feng X, et al. Minor population of CD55CD59-blood cells predicts response to immunosuppressive therapy and prognosis in patients with aplastic anemia. Blood. 2006;107: 1308-1314.

32. Socié G, Mary JY, de Gramont A, et al. Paroxysmal nocturnal haemoglobinuria: long-term follow-up and prognostic factors. French Society of Haematology. Lancet. 1996;348:573-577.

33. de Latour RP, Mary JY, Salanoubat C, et al; French Society of Hematology; French Association of Young Hematologists. Paroxysmal nocturnal hemoglobinuria: natural history of disease subcategories. Blood. 2008;112:3099-3106.

34. Lee WJ, Jang JH, Kim JS, et al. Clinical signs and symptoms associated with increased risk for thrombosis in patients with paroxysmal nocturnal hemoglobinuria from a Korean Registry. Int J Hematol. 2013;97: 749-757.

35. Weitz I, Meyers G, Lamy T, et al. Cross-sectional validation study of patient-reported outcomes in patients with paroxysmal nocturnal haemoglobinuria. Intern Med J. 2013;43:298-307.

36. Hill A, Sapsford RJ, Scally A, et al. Under-recognized complications in patients with paroxysmal nocturnal haemoglobinuria: raised pulmonary pressure and reduced right ventricular function. Br J Haematol. 2012;158:409-414.

37. Hill A, Rother RP, Wang X, et al. Effect of eculizumab on haemolysis-associated nitric oxide depletion, dyspnoea, and measures of pulmonary hypertension in patients with paroxysmal nocturnal haemoglobinuria. Br J Haematol. 2010;149:414-425.

38. Louwes H, Vellenga E, de Wolf JT. Abnormal platelet adhesion on abdominal vessels in a symptomatic patients with paroxysmal nocturnal hemoglobinuria. Ann Hematol. 2001;80:573-576.

39. Clark DA, Butler SA, Braren V, Hartmann RC, Jenkins DE Jr. The kidneys in paroxysmal nocturnal hemoglobinuria. Blood. 1981;57: 83-89.

40. Hillmen P, Elebute M, Kelly R, et al. Long-term effect of the complement inhibitor eculizumab on kidney function in patients with paroxysmal nocturnal hemoglobinuria. Am J Hematol. 2010;85: 553-559.

41. Le XF, Yang TY, Yang XY, Wang XM. Characteristics of paroxysmal nocturnal hemoglobinuria in China. Clinical analysis of 476 cases. Chin Med J (Engl). 1990;103:885-889.

42. Nafa K, Bessler M, Mason P, et al. Factor V Leiden mutation investigated by amplification created restriction enzyme site (ACRES) in PNH patients with and without thrombosis. Haematologica. 1996;81: 540-542.

43. Gostynski M, Engelter S, Papa S, Ajdacic-Gross V, Gutzwiller F, Lyrer P. Incidence of first-ever ischemic stroke in the Canton Basle-City, Switzerland: a population-based study 2002/2003. J Neurol. 2006;253:86-91.

44. Almeida AM, Murakami Y, Baker A, et al. Targeted therapy for inherited GPI deficiency. N Engl J Med. 2007;356:1641-1647.

45. Hugel B, Socié G, Vu T, et al. Elevated circulating microparticles in patients with paroxysmal nocturnal hemoglobinuria and aplastic anemia. Blood. 1999;93:3451-3456.

46. Liebman HA, Feinstein DI. Thrombosis in patients with paroxysmal nocturnal hemoglobinuria is associated with markedly elevated plasma levels of leucocyte derived tissue bearing microparticles. Thromb Res. 2003;111:235-238. 
47. Simak J, Holada K, Risitano AM, Zivny JH, Young NS, Vostal JG. Elevated circulating endothelial membrane microparticles in paroxysmal nocturnal haemoglobinuria. Br J Haematol. 2004;125:804-813.

48. Laurence J. Atypical hemolytic uremic syndrome (aHUS): making the diagnosis. Clin Adv Hematol Oncol. 2012;10(10 Suppl 17):1-12.

49. Fang CJ, Richards A, Liszewski MK, Kavanagh D, Atkinson JP. Advances in understanding of the pathogenesis of aHUS and HELLP. Br J Haematol. 2008;143:336-348.

50. Tichaczek-Goska D. Deficiencies and excessive human complement system activation in disorders of multifarious etiology. Adv Clin Exp Med. 2012;21:105-114.

51. Frimat M, Tabarin F, Dimitrov JD, et al. Complement activation by heme as a secondary hit for atypical hemolytic uremic syndrome. Blood. 2013;122:282-292.

52. Helley D, de Latour RP, Porcher R, et al. Evaluation of hemostasis and endothelial function in patients with paroxysmal nocturnal hemoglobinuria receiving eculizumab. Haematologica. 2010;95:574-581.

53. Maroney SA, Mast AE. Expression of tissue factor pathway inhibitor by endothelial cells and platelets. Transfus Apher Sci. 2008;38:9-14.

54. Ariëns RA, Alberio G, Moia M, Mannucci PM. Low levels of heparin-releasable tissue factor pathway inhibitor in young patients with thrombosis. Thromb Haemost. 1999;81:203-207.

55. Grünewald M, Siegemund A, Grünewald A, et al. Plasmatic coagulation and fibrinolytic system alterations in PNH: relation to clone size. Blood Coagul Fibrinolysis. 2003;14:685-695.

56. Redecha P, Tilley R, Tencati M, et al. Tissue factor: a link between C5a and neutrophil activation in the antiphospholipid syndrome. Blood. 2007;110:2423-2431.

57. Shao Z, Nishimura T, Leung LL, Morser J. Carboxypeptidase B2 deficiency reveals opposite effects of complement $\mathrm{C} 3 \mathrm{a}$ and $\mathrm{C} 5 \mathrm{a}$ in a murine polymicrobial sepsis model. J Thromb Haemost. 2015;13: 1090-1102.

58. Davila M, Amirkhosravi A, Coll E, et al. Tissue factor-bearing microparticles derived from tumor cells: impact on coagulation activation. J Thromb Haemost. 2008;6:1517-1524.

59. Del Conde I, Bharwani LD, Dietzen DJ, Pendurthi U, Thiagarajan P, López JA. Microvesicle-associated tissue factor and Trousseau's syndrome. J Thromb Haemost. 2007;5:70-74.

60. Zwicker JI, Liebman HA, Neuberg D, et al. Tumor-derived tissue factorbearing microparticles are associated with venous thromboembolic events in malignancy. Clin Cancer Res. 2009;15:6830-6840.

61. Wojta J, Kaun C, Zorn G, et al. C5a stimulates production of plasminogen activator inhibitor- 1 in human mast cells and basophils. Blood. 2002;100:517-523.
62. Ritis K, Doumas M, Mastellos D, et al. A novel C5a receptor-tissue factor cross-talk in neutrophils links innate immunity to coagulation pathways. J Immunol. 2006;177:4794-4802.

63. Geddings JE, Mackman N. New players in haemostasis and thrombosis. Thromb Haemost. 2014;111:570-574.

64. Zuber J, Fakhouri F, Roumenina LT, Loirat C, Frémeaux-Bacchi V; French Study Group for aHUS/C3G. Use of eculizumab for atypical haemolytic uraemic syndrome and C3 glomerulopathies. Nat Rev Nephrol. 2012;8:643-657.

65. Rother RP, Rollins SA, Mojcik CF, Brodsky RA, Bell L. Discovery and development of the complement inhibitor eculizumab for the treatment of paroxysmal nocturnal hemoglobinuria. Nat Biotechnol. 2007;25:1256-1264.

66. Kelly R, Arnold L, Richards S, et al. The management of pregnancy in paroxysmal nocturnal haemoglobinuria on long term eculizumab. $\mathrm{Br} J$ Haematol. 2010;149:446-450.

67. Kanakura Y, Ohyashiki K, Shichishima T, et al. Safety and efficacy of the terminal complement inhibitor eculizumab in Japanese patients with paroxysmal nocturnal hemoglobinuria: the AEGIS clinical trial. Int J Hematol. 2011;93:36-46.

68. Hill A, Hillmen P, Richards SJ, et al. Sustained response and long-term safety of eculizumab in paroxysmal nocturnal hemoglobinuria. Blood. 2005;106:2559-2565.

69. Kelly RJ, Hill A, Arnold LM, et al. Long term treatment with eculizumab in paroxysmal nocturnal hemoglobinuria: sustained efficacy and improvement in survival. Blood. 2011;117:6786-6792.

70. Nishimura J, Yamamoto M, Hayashi S, et al. Genetic variants in C5 and poor response to eculizumab. N Engl J Med. 2014;370:632-639.

71. Peffault de Latour R, Fremeaux-Bacchi V, Porcher R, et al. Assessing complement blockade in patients with paroxysmal nocturnal hemoglobinuria receiving eculizumab. Blood. 2015;125:775-783.

72. Risitano AM, Notaro R, Marando L, et al. Complement fraction 3 binding on erythrocytes as additional mechanism of disease in paroxysmal nocturnal hemoglobinuria patients treated by eculizumab. Blood. 2009;113:4094-4100.

73. Morita Y, Nishimura J, Shimada T, et al. Successful anticoagulant therapy for two pregnant PNH patients, and prospects for the eculizumab era. Int J Hematol. 2013;97:491-497.

74. Vekemans MC, Lambert C, Ferrant A, et al. Management of pregnancy in paroxysmal nocturnal hemoglobinuria on long-term eculizumab. Blood Coagul Fibrinolysis. 2015;26:458-463.

75. Kelly RJ, Höchsmann B, Szer J, et al. Eculizumab use in pregnancy in patients with paroxysmal nocturnal hemoglobinuria. $N$ Engl $\mathrm{J} \mathrm{Med}$. Epub.
Orphan Drugs: Research and Reviews

\section{Publish your work in this journal}

Orphan Drugs: Research and Reviews is an international, peer-reviewed, open access journal publishing original research, reports, reviews and commentaries on all areas of the design and development of orphan drugs for the treatment of rare diseases through to clinical applications Clinical outcomes, patient safety, and programs for the development and

\section{Dovepress}

effective, safe, and sustained use of medicines will be a feature of the journal. The manuscript management system is completely online and includes a very quick and fair peer-review system, which is all easy to use. Visit http://www.dovepress.com/testimonials.php to read real quotes from published authors. 